\title{
Evaluation of Ferryl Formation by Electrocatalytic Oxidation of Alkene Using Luminol Chemiluminescence
}

\author{
Mohammad Sohel RanA* and Keietsu TAMAgaKe \\ Faculty of Pharmaceutical Sciences, Okayama University; Okayama 700_8530, Japan.
}

Received November 4, 2004; accepted February 2, 2005

Electrochemical formation of ferryl porphyrin was examined by electrocatalytic oxidation of alkene by measuring luminol chemiluminescence using a flow-injection method. Emission was observed both below the reduction potential of $\mathrm{Fe}^{\mathrm{III}} \mathrm{TMPyP}(-0.08 \mathrm{~V}$ at $\mathrm{pH} 11,-0.02 \mathrm{~V}$ at $\mathrm{pH} 7$ and $0.15 \mathrm{~V}$ at $\mathrm{pH} 3)$ and above the oxidation potential (0.6 V at pH 11, $0.75 \mathrm{~V}$ at $\mathrm{pH} 7$ and $1.1 \mathrm{~V}$ at $\mathrm{pH} 3)$. However, both anodic and cathodic emissions were inhibited significantly by the addition of alkene (cyclopent-2-ene-1-acetic acid) solutions downstream of the working electrode. Further, the spectra at both anodic and cathodic sides shifted to the longer wavelength $(>424 \mathrm{~nm})$ compared to the original spectrum of $\mathrm{Fe}^{\mathrm{III}} \mathrm{TMPyP}(422 \mathrm{~nm})$, which was not observed with the addition of alkene solution. Therefore, the results suggest that the electrochemically generated oxo-ferryl species have been engaged in catalytic oxidation of alkene before the flow reaches the observation cell.

Key words ferryl formation; iron porphyrin; alkene oxidation; electrochemical reduction; luminol chemiluminescence

Electrochemical formation and characterization of highvalent metalloporphyrins have been of interest for a long time because of their central roles in a number of important biological processes. ${ }^{1,2)}$ Formation of a high-valent oxo-metal complex is essential in these catalytic reactions. It can be achieved either by a reduction in the presence of molecular oxygen or by applying a strong oxidant for metalloporphyrins. Many such metalloporphyrin complexes have been synthesized for mimicking these biological reactions, but most were studied in non-aqueous systems. ${ }^{3,4)}$ The generation of oxo-ferryl porphyrins in aqueous solutions by a number of chemical methods has been reported. ${ }^{5,6)}$ Recently, it was also reported that ferryl porphyrin can be produced by the reduction of ferric porphyrin to ferrous porphyrin by dithionite followed by autoxidation of ferrous porphyrin in the presence of molecular oxygen. ${ }^{7}$ )

We have been working on electrochemical formation of ferryl porphyrin in aqueous solution to avoid possible interference due to excess reactants or secondary products in the chemical system. A number of electrochemical methods have been reported for the generation of oxo-ferryl porphyrins in aqueous $^{8)}$ and non-aqueous ${ }^{9)}$ solutions. However, all of these methods were limited to the direct electrochemical oxidation of iron(III) porphyrin by applying higher anodic potentials. In this work, using a flow-injection method, we detected the formation of ferryl porphyrin by electrochemical reduction of iron(III) porphyrin in aqueous solution. In order to estimate the electrochemical formation of oxo-ferryl porphyrin, the measurement of luminol chemiluminescence was employed $^{7,10)}$ as it was demonstrated to have relatively higher production of light and greater sensitivity. ${ }^{11)}$ Detection of ferryl porphyrin was also achieved by measuring its absorption spectrum.

High-valent iron porphyrins exhibit different activities towards alkene oxidations in aqueous media. The catalytic oxidation of a series of water-soluble carboxylic alkenes via a pathway of allylic hydrogen abstraction in the presence of molecular oxygen has been reported. ${ }^{12)}$ By this process the oxo-ferryl porphyrins returned into their original form, ferric porphyrins (Eq. 1). We attempted to monitor the electro- chemical formation of oxo-ferryl porphyrin by supplying alkene solutions downstream to the working electrode under aerated conditions. Alkene oxidation catalyzed by oxo-ferryl porphyrin was interpreted by the quenching rate of luminol chemiluminescence.

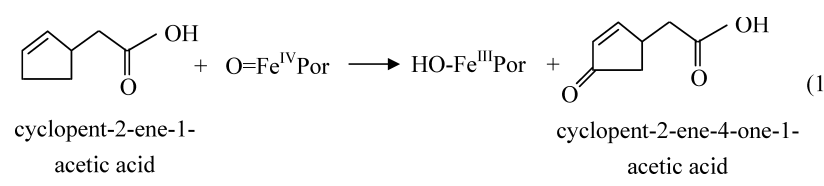

We have selected alkene, cyclopent-2-ene-1-acetic acid in this experiment for its higher reaction rate with oxo-ferryl porphyrin. It has been reported that electrochemically generated $\mathrm{O}=\mathrm{Fe}^{\mathrm{IV}} \mathrm{TMPyP}$ reacts readily with cyclopent-2-ene-1acetic acid and is then reduced back to HO-Fe ${ }^{\mathrm{III}} \mathrm{TMPyP} .{ }^{12}$ )

\section{Experimental}

Materials Synthesis The solution of Fe ${ }^{\mathrm{III}} \mathrm{TMPyP}$ (Mid-Century Laboratories) was prepared in the appropriate buffer or in an un-buffered acid/base at desired pH. $0.2 \mathrm{~mm}$ luminol solutions were prepared in $0.1 \mathrm{M} \mathrm{Na}_{2} \mathrm{CO}_{3}$ aqueous buffer to keep the $\mathrm{pH}$ of the observation cell favorable for emission. Buffer solutions (20 mM) were prepared from $\mathrm{HClO}_{4}$, phosphate, carbonate and $\mathrm{NaOH}$ for the $\mathrm{pH}$ range of $0-14$. Supporting electrolytes include $0.1 \mathrm{M}$ $\mathrm{Na}_{2} \mathrm{SO}_{4}$ or $\mathrm{NaClO}_{4}$. The $\mathrm{pH}$ values were measured with a TOA HM-20S $\mathrm{pH}$ meter. Luminol (Ishizu Seiyaku Ltd.) and cyclopent-2-ene-1-acetic acid (Aldrich Chemical Co.) were used as received. The other reagents used were of the highest purity available. Deoxygenation was achieved by purging with highly pure $\mathrm{N}_{2}$ gas.

Experimental Methods Chemiluminescence and spectrophotometric experiments were performed with a laboratory constructed flow-injection apparatus (Fig. 1)

Iron(III) porphyrin and buffer solutions were passed through channel 1 (ch1) and channel $2(\operatorname{ch} 2)$ respectively, which were then mixed in a ratio of $1: 1$ by volume before undergoing electrochemical reaction at the working electrode. The electrochemically generated species were mixed within $1 \mathrm{~s}$ with aerated luminol solution, supplied through channel $3(\mathrm{ch} 3)$ to give emission. All experiments were carried out at a continuous flow rate of $2.7 \mathrm{ml} / \mathrm{min}$, controlled by a 4-channel Ismatec ${ }^{\circledR}$ Reglo-Digital pump (Model ISM-834).

Electrochemistry and Chemiluminescence Luminol chemiluminescence was measured with a photomultiplier via an optical fiber mounted with an observation cell and amplified by changing the sensitivity of the Jasco photometer. A cyclic voltammogram along with the emission intensity were measured with a laboratory-constructed potentiostat and were recorded simultaneously by a computer-controlled instrument. Cyclic voltammetry 


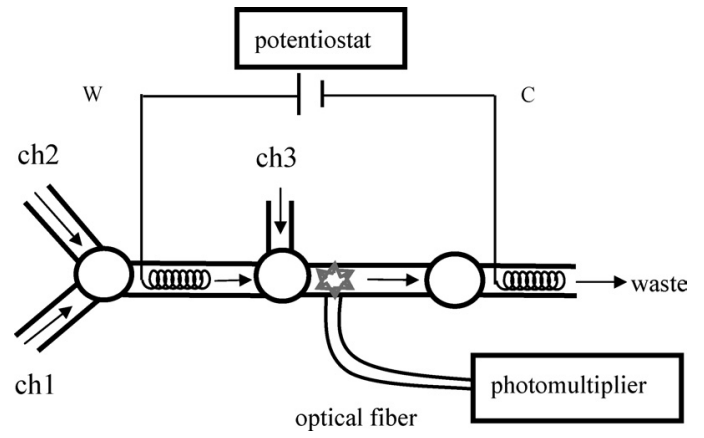

Fig. 1. Schematic Diagram of the Flow-Injection Apparatus

was conducted using a three-electrode cell in which a glassy carbon rod was used as the working electrode. A platinum wire was used as the counter electrode and a home-made $\mathrm{Ag} / \mathrm{AgCl} / \mathrm{KCl}$ (sat) electrode as the reference electrode.

Absorption Spectroscopy Absorption spectra, as a function of potentials, were measured with a Hewlett Packard Model 8450A diode array spectrophotometer. The sample was introduced into the spectrophotometric cell within $1-2 \mathrm{~s}$ through a narrow tube downstream to the working electrode of the flow-injection apparatus (Fig. 1). The sets of spectra were analyzed using software DPR, developed in our laboratory.

\section{Results and Discussion}

The electrochemical behavior of the Fe ${ }^{\mathrm{III}} \mathrm{TMPyP}$ complexes in aqueous solutions has been extensively studied. ${ }^{13,14)}$ We report here the generation and characterization of highvalent iron porphyrins induced by electrochemical reduction of $\mathrm{Fe}^{\mathrm{III}} \mathrm{TMPyP}$ using luminol chemiluminescence and absorption spectrum. A laboratory constructed flow-injection system operated by a 4-channel digital pump was used in this study to obtain a uniform and continuous supply of reagent solutions.

Electrochemical reduction of Fe ${ }^{\mathrm{III}} \mathrm{TMPyP}$ was conducted in $0.1 \mathrm{M} \mathrm{Na} \mathrm{NO}_{4}$ aqueous solutions on a carbon electrode. Figure 2 shows the emission intensity of $10 \mu \mathrm{M} \mathrm{Fe}{ }^{\mathrm{III}} \mathrm{TMPyP}$ as a function of potential in three different acidic conditions.

It can be clearly seen that emissions were observed both below the reduction potential of Fe $\mathrm{Fe}^{\mathrm{III}} \mathrm{TMPyP}(-0.08 \mathrm{~V}$ at $\mathrm{pH}$ $11,-0.02 \mathrm{~V}$ at $\mathrm{pH} 7$ and $0.15 \mathrm{~V}$ at $\mathrm{pH} 3$ ) and above the oxidation potential $(0.6 \mathrm{~V}$ at $\mathrm{pH} 11,0.75 \mathrm{~V}$ at $\mathrm{pH} 7$ and $1.1 \mathrm{~V}$ at $\mathrm{pH}$ 3) where $\mathrm{Fe}^{\mathrm{II}}$ and $\mathrm{Fe}^{\mathrm{IV}}$ species were expected to be the first electrochemical products. The onset of emission shifted to a more negative potential as the $\mathrm{pH}$ increased. According to an earlier report, ${ }^{15)}$ the actual product formed at the anodic region was ferryl or $\mathrm{O}=\mathrm{Fe}^{\mathrm{IV}} \mathrm{TMPyP}$. In our laboratory, the formation of $\mathrm{O}=\mathrm{Fe}^{\mathrm{IV}} \mathrm{TMPyP}$ induced by electrochemical reduction of $\mathrm{Fe}^{\mathrm{III}} \mathrm{TMPyP}$ has been confirmed in aqueous solutions. Fe ${ }^{\mathrm{II}} \mathrm{TMPyP}$, electro-generated by one-electron $\left(1 \mathrm{e}^{-}\right)$reduction of Fe ${ }^{\text {III }}$ TMPyP, was autoxidized in the presence of molecular oxygen to form $\mathrm{O}=\mathrm{Fe}^{\mathrm{IV}} \mathrm{TMPyP}$. Ferryl is widely accepted to be the species responsible for stimulating emission in the hydrogen peroxide + iron porphyrin + luminol system. ${ }^{7)}$ So it is expected that the luminol chemiluminescence observed under both reductive and oxidative conditions resulted due to ferryl formation.

However, the luminol chemiluminescence produced by the electrochemical reaction of Fe ${ }^{\mathrm{III}} \mathrm{TMPyP}$ was significantly quenched when the alkene solutions were added by making another channel between the working electrode and luminol

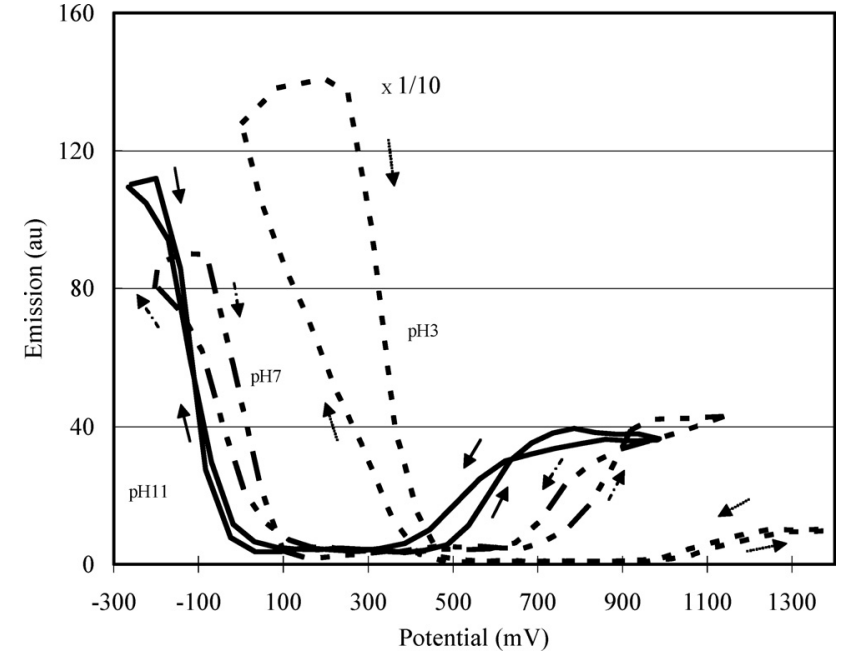

Fig. 2. Emission Intensity of $10 \mu \mathrm{M} \mathrm{Fe}{ }^{\mathrm{III}} \mathrm{TMPyP}$ as a Function of Applied Potential at Working Electrode in the $\mathrm{pH} 3(\cdots \cdots)$, pH $7\left(\left(^{-}-\right)\right.$and $\mathrm{pH} 11(-)$ Buffer Solutions

Scan rate $1 \mathrm{mV} / \mathrm{s}$.

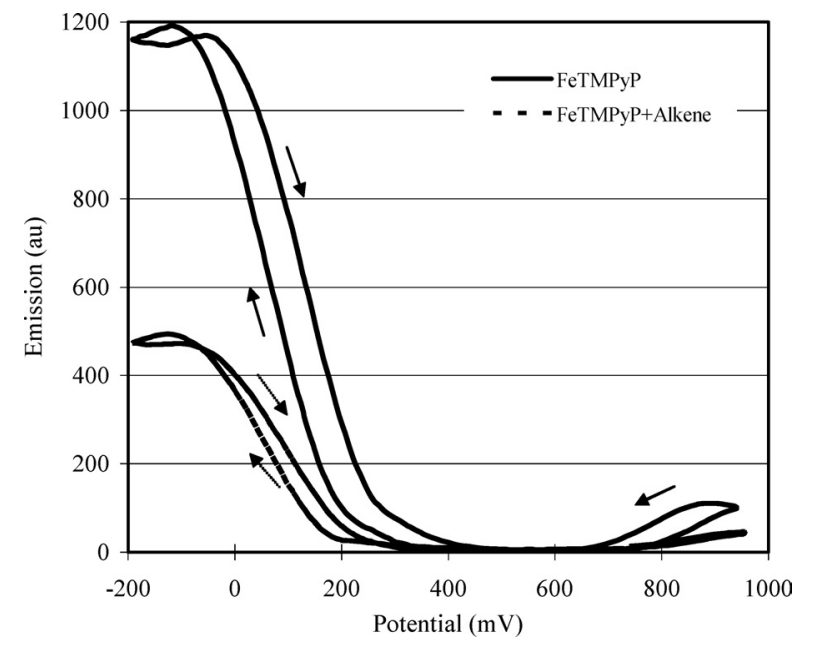

Fig. 3. Emission Intensity Observed as a Function of Potential for $10 \mu \mathrm{M}$ $\mathrm{Fe}^{\mathrm{III}} \mathrm{TMPyP}$ with and without $10 \mu \mathrm{M}$ Alkene Solutions under Aerated Condition at $\mathrm{pH} 4$

Scan rate $1 \mathrm{mV} / \mathrm{s}$. Sample flow rate $2.7 \mathrm{ml} / \mathrm{min}$.

inlet (Fig. 1). Figure 3 shows the emission intensity of $10 \mu \mathrm{M}$ $\mathrm{Fe}^{\mathrm{III}} \mathrm{TMPyP}$ solution produced as a function of potentials and the effect of alkene in quenching that emission intensity in the buffer solutions of $\mathrm{pH} 4$.

Since the electrochemical response of Fe ${ }^{\mathrm{III}} \mathrm{TMPyP}$ depends on the acidity of the supporting solutions, ${ }^{16)}$ the emission intensity was also found to be $\mathrm{pH}$ dependent (as shown in Fig. 2 ). Keeping all the conditions as above, the emission observed at both the cathodic and anodic sides with and without alkene in different $\mathrm{pH}$ solutions are presented in the Table 1.

From Fig. 3, it can be seen that the emission intensity at both cathodic and anodic conditions has been quenched by about $65 \%$ with the addition of alkene. The results observed are almost the same over the entire $\mathrm{pH}$ range (Table 1), except under strong alkaline conditions $(\mathrm{pH} \mathrm{12)}$ where the intensity decreased about $80 \%$. This can be explained by the earlier report ${ }^{12)}$ that the reaction rate of $\mathrm{O}=\mathrm{Fe}^{\mathrm{IV}} \mathrm{TMPyP}(\mathrm{OH})$ 
Table 1. Emission Observed (au) with and without Alkene Solution of $10 \mu \mathrm{M}$ in Different $\mathrm{pH}$

\begin{tabular}{llrrrrr}
\hline \hline & & pH 2 & pH 4 & pH 7 & pH 9 & pH 12 \\
\hline Cathodic & Fe $^{\mathrm{III}}$ TMPyP & 2100 & 1150 & 55 & 90 & 160 \\
& $\mathrm{Fe}^{\mathrm{III}}$ TMPyP+alkene & 650 & 450 & 20 & 25 & 35 \\
\multirow{3}{*}{ Anodic } & $\mathrm{Fe}^{\mathrm{III}}$ TMPyP & 40 & 80 & 120 & 140 & 90 \\
& $\mathrm{Fe}^{\mathrm{III}}$ TMPyP+alkene & 0 & 25 & 30 & 35 & 25 \\
\hline
\end{tabular}

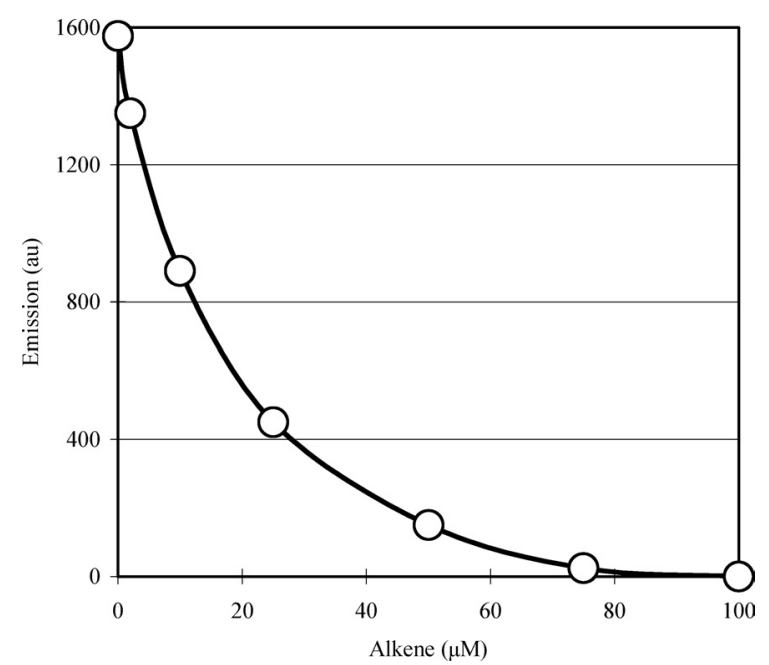

Fig. 4. Emission Intensity with Different Concentrations of Alkene at $\mathrm{pH}$ 12.0

with alkene is higher than that of $\mathrm{O}=\mathrm{Fe}^{\mathrm{IV}} \mathrm{TMPyP}$. Although the emission was not quenched completely with alkene, perhaps due to an inadequate concentration of alkene or an insufficient reaction time, it can be considered as evidence of the formation of oxo-ferryl species in this system.

Meanwhile, the effect of alkenes in diminishing the luminol chemiluminescence was found to be concentration-dependent. Experimental results with different concentrations of alkene in the buffer solutions of pH 12 are shown in Fig. 4.

It can be clearly observed that emission decreased in accordance with the increase in alkene concentrations. Similar results were obtained for all other $\mathrm{pH}$ examined, but as reported $^{9)}$ the activity was found to be maximum at higher $\mathrm{pH}$ (data not shown).

This is justified further by the observations of the spectrophotometric analysis carried out under the same conditions. Figure 5 shows the spectral change in Fe ${ }^{\mathrm{III}}$ TMPyP solution as a function of potentials with and without alkene at $\mathrm{pH} 11$.

The shift of absorption spectra towards a longer wavelength under aerated conditions was not observed when alkene solution was added downstream to the working electrode (data presented in Fig. 5). Hence, the results suggest that the electrochemically-generated oxo-ferryl species are engaged in catalytic oxidation of alkene. In the process, oxoferryl species returned into ferric form before it reaches at the observation cell.

The chemiluminescence pattern was also checked by using other water-soluble carboxylic acids like 2,3-dimethylacrylic acid, 3-methylacrylic acid and methacrylic acid, and all were found to be positive in quenching emission. On the other

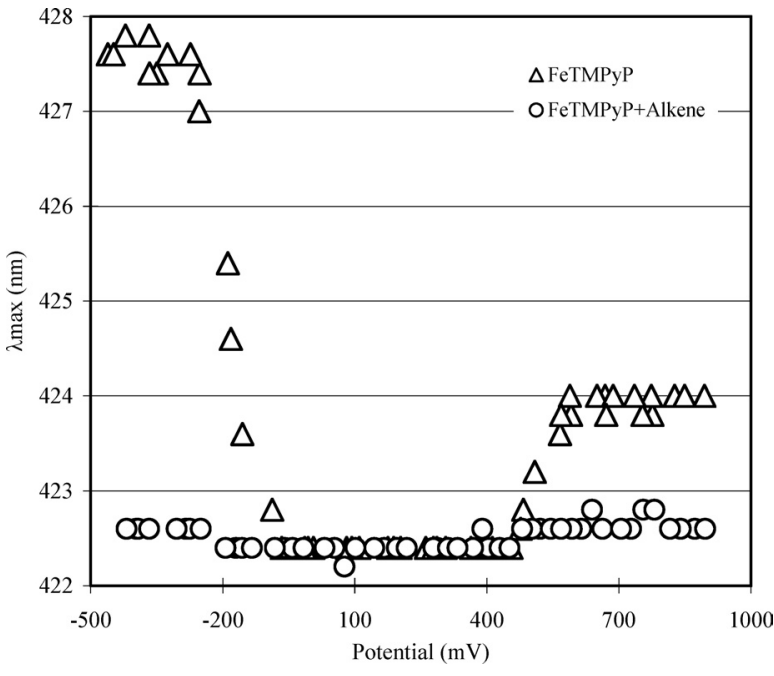

Fig. 5. Shift of Wavelength as a Function of Potential for $5 \mu \mathrm{M} \mathrm{Fe}$ TMPyP with and without Alkene under Aerated Condition at $\mathrm{pH} 11$

Scan rate $1 \mathrm{mV} / \mathrm{s}$. Measuring interval $60 \mathrm{~s}$.

hand, cyclopentyl acetic acid, which is inactive in electrocatalytic oxidation, showed no effect on chemiluminescence.

Concluding Remarks $\mathrm{O}=\mathrm{Fe}^{\mathrm{IV}} \mathrm{TMPyP}$ formation induced by electrochemical reduction of $\mathrm{Fe}^{\mathrm{III}} \mathrm{TMPyP}$ has been confirmed by electrocatalytic oxidation of alkene. Chemiluminescence were observed at both the anodic and cathodic potentials as a function of the potentials over the wide range of $\mathrm{pH}$ inhibited by the addition of alkene solutions. Absorption spectrum of $\mathrm{O}=\mathrm{Fe}^{\mathrm{IV}} \mathrm{TMPyP}$ at $436 \mathrm{~nm}$ in the $\mathrm{pH} 11$ aqueous buffer solution was not observed in the presence of alkene. Therefore, the results were considered to be evidence of $\mathrm{O}=\mathrm{Fe}^{\mathrm{IV}} \mathrm{TMPyP}$ formation. Conversely, the method of luminol chemiluminescence is expected to be useful for monitoring high-valent metalloporphyrin-induced electrocatalytic oxidations of alkene or other substrates.

\section{References}

1) Groves J. T., Nemo T. E., Myers R. S., J. Am. Chem. Soc., 101, 1032 1042 (1979).

2) Sheldon R. A., "Metalloporphyrins in Catalytic Oxidations," Marcel Dekker, New York, 1994.

3) Dolphin D., "The Porphyrins," Academic Press, New York, 1978

4) Guilard R., Kadish K. M., Chem. Rev., 88, 1121 -1138 (1988).

5) Shedbalker V. P., Modi S., Mitra S., J. Chem. Soc. Chem. Commun., 1988, 1238-1247 (1988).

6) Anelli P. L., Banfi S., Legramandi F., Montanari F., Pozzi G., Quici S. J. Chem. Soc. Perkin Trans. 1, 1993, 1345-1354 (1993).

7) Saha T. K., Karmaker S., Tamagake K., Manuscript in preparation.

8) Chen S.-M., Su Y. O., J. Chem. Soc. Chem. Commun., 1990, 491-495 (1990).

9) Groves J. T., Gross Z., Stern M., Inorg. Chem., 33, 5065-5071 (1994).

10) Seitz W. R., Methods Enzymol., 57, 445-450 (1978).

11) Wandell G. J., Stedman D. H., Cantreu C. A., Anal Chem., 55, 937943 (1983).

12) Creager S. E., Rayback S. A., Murray R. W., J. Am. Chem. Soc., 108, 4225-4233 (1986).

13) Chen S.-M., Sun P.-J., Su Y. O., J. Electroanal. Chem., 294, 151-157 (1990).

14) Rogers K. R., Reed R. A., Su Y. O., Spiro T. G., Inorg. Chem., 31, 2688-2695 (1992).

15) Creager S. E., Murray R. W., Inorg. Chem., 24, 3824-3830 (1985).

16) Chen S.-M., Chiu S.-W., Electrochim. Acta, 45, 4399-4406 (2000). 